\title{
The Influence of Environment on Antigen Production by Pasteurella pestis Studied by Means of the Continuous Flow Culture Technique
}

\author{
By S. J. PIRT, E. J. THACKERAY AND R. HARRIS-SMITH \\ Microbiological Research Establishment, Porton, Salisbury, Wiltshire
}

(Received 16 November 1960)

\begin{abstract}
SUMMARY
The yields of three antigens of Pasteurella pestis (fraction I, antigen 4, V antigen) in continuous flow culture over a range of temperature and $\mathrm{pH}$ values have been determined quantitatively. The production of some other antigens was followed qualitatively. The production of fraction I, V antigen and antigen 4 was greatest at $37^{\circ}$ and little or none at $28^{\circ}$. The production of antigen 4 required an environmental $\mathrm{pH}$ below 6.9. The production of antigen 5 showed oxygen dependence at $28^{\circ}$ but not at $37^{\circ}$. In transitions from one antigenic state to another the amounts of some antigens in the organism passed through maxima. Selection against types with the $\mathrm{V}$ and fraction $\mathrm{I}$ antigens occurred during growth at $37^{\circ}$, but not at $28^{\circ}$. Selection against types with antigen 4 did not occur.
\end{abstract}

\section{INTRODUCTION}

To produce organisms of constant antigenic composition, quantitatively and qualitatively, strict control of environment would seem to be necessary. We became interested in this problem because of the need to control the antigenic composition of Pasteurella pestis in studies of the immunogenicity and virulence of this organism. Continuous flow culture rather than batch culture was used because of the possibility of maintaining a given environment indefinitely in the continuous system. Consideration of the differences between a batch process and a continuous process leads one to expect that the two techniques may give organisms of different antigenic composition. This may result because, in the course of the batch process, especially one which requires a complex medium (as pathogenic bacteria usually do) there may be environmental changes (in available nutrients or in physical factors such as $\mathrm{pH}$ value) unless adequate control equipment is available. Different antigens may be produced at different stages in batch culture; $\boldsymbol{P}$. pestis provides an example of this (Crumpton \& Davies, 1956). On the other hand, in a continuous flow culture one can select any environment from that of the log phase to the stationary phase and maintain it indefinitely, but one may then find that, because the organisms grow in only one environment, not all the antigens can be produced at once. The way out of this difficulty should be to use a multi-stage process (Pirt \& Callow, 1959; Callow \& Pirt, 1961). Data about these problems is provided by the present work. The lack of control over, and the variation of conditions in batch culture may explain why, with rare exceptions, the published work on the antigenic 
composition of micro-organisms does not indicate that variation in environment is a reliable way of altering the antigenic composition. The problem of the effect of environment was taken up by Lacey (1953) who found that reversible changes in the antigenic composition of Haemophilus spp. could be induced by variation in the proportions of $\mathrm{Na}, \mathrm{Mg}, \mathrm{Cl}$ and $\mathrm{SO}_{4}$ ions, and in the temperature of the medium. Ogburn, Harris \& Harris (1958) used a continuous flow technique to show that an extracellular antigen of a haemolytic streptoccocus required an acid $\mathrm{pH}$ value for its formation. Striking examples of the effects of environment on antigenic composition have been found with Paramecium aurelia (Beale, 1954) where the antigenic composition is a function of the temperature, the inorganic salt composition of the growth medium and the amount of nutrients supplied.

The earliest recognition of the effect of an environmental factor on antigen production by Pasteurella pestis seems to have been that of Schütze (1932) who found that the envelope antigen (now known as fraction I) was produced at $37^{\circ}$ but not at $26^{\circ}$, although earlier Rowland (1914) had recognized the temperature dependence of envelope formation. For an historical review of the antigenic analysis of $\boldsymbol{P}$. pestis reference should be made to Crumpton \& Davies (1956). These authors, by application of gel diffusion analysis, revealed the presence of seven new antigens. One of these antigens was antigen 4, later characterized in greater detail and shown to be of immunogenic importance (Crumpton \& Davies, 1957). The requirements for antigen 4 production seemed to be exacting because, although produced in an aerated broth galactose medium at $37^{\circ}$, the antigen did not appear in the organisms until $16 \mathrm{hr}$. after the initiation of growth. This antigen was also absent from organisms grown as surface cultures on broth agar. An explanation of this behaviour is provided by our results. Further development of knowledge about $\boldsymbol{P}$. pestis antigens came from the recognition by Burrows \& Bacon (1956) of the $\mathrm{V}$ and $\mathrm{W}$ antigens as characteristic of the virulent strains. The present work has three parts: quantification of the effects of $\mathrm{pH}$ value and temperature on antigen production; a description of some transitional stages when the antigenic composition is changed by the environment; some effects of variation and selection on antigenic composition in long-term cultures and their control by the environment.

\section{METHODS}

For descriptions of methods other than those given below reference should be made to Pirt \& Callow (1958). The method of dry wt. determination was used with formolized samples (HCHO concn. $3 \%, \mathrm{w} / \mathrm{v}$ ).

Continuous flow-culture technique. The culture apparatus was based on that of Elsworth, Meakin, Pirt \& Capell (1956) and Callow \& Pirt (1961), but modified to ensure safety in work with these pathogenic organisms. The medium flow rate was $0 \cdot 1$ culture volumes $/ \mathrm{hr}$. (dilution rate $0 \cdot 1 \pm 0 \cdot 005 \mathrm{hr}^{-1}$ ); hence the generation time of the organisms was $6.9 \mathrm{hr}$. in the steady state.

The $\mathrm{pH}$ value was controlled by the automatic addition of $2 \mathrm{~N}-\mathrm{NaOH}$ or $2 \mathrm{~N}-\mathrm{H}_{2} \mathrm{SO}_{4}$ (Callow \& Pirt, 1956); the pH controller (Fielden Ltd., Paston Road, Wythenshawe, Manchester) controlled within $\pm \mathbf{0 \cdot 1 5} \mathrm{pH}$ units. Temperature was controlled within $\pm 0.5^{\circ}$ : changes in $\mathrm{pH}$ value and in temperature were made gradually at rates of $0 \cdot 1 \mathrm{pH}$ unit or $1^{\circ} / 4 \mathrm{hr}$. 
Media. The liquid medium contained (g./l.): casein acid hydrolysate (Oxoid) 15.0; L-cysteine monohydrochloride, 0.32 ; glycine, 1.5 ; glucose, $12.0 ; \mathrm{KH}_{2} \mathrm{PO}_{4}$, $0.85 ; \mathrm{Na}_{2} \mathrm{HPO}_{4} .2 \mathrm{H}_{2} \mathrm{O}, 8 \cdot 0$; trisodium citrate dihydrate, $3.48 ; \mathrm{MgSO}_{4} .7 \mathrm{H}_{2} \mathrm{O}, 0.6$; $\mathrm{FeSO}_{4} .7 \mathrm{H}_{2} \mathrm{O}, 0 \cdot 03 ; \mathrm{MnSO}_{4} .4 \mathrm{H}_{2} \mathrm{O}, 0 \cdot 02 ; \mathrm{CaCl}_{2}, 0 \cdot 0224$. The final $\mathrm{pH}$ value was $7 \cdot 4$. Sterilization was by autoclaving $\left(126^{\circ}\right.$ for $20 \mathrm{~min}$.); the glucose and cysteine solutions added were sterilized separately.

Either Alkaterge-C (Commercial Solvents Corp., Terre Haute, Indiana, U.S.A.) $\mathbf{5 0} \%(\mathrm{v} / \mathrm{v})$ in liquid paraffin, or silicone antifoam B (Midland Silicones, Ltd) $\mathbf{2 5} \%$ $(\mathrm{w} / \mathrm{v})$ was added as an antifoam.

The solid medium contained agar with tryptic digest of meat to which $5 \%$ of its volume of Fildes peptic digest of sheep's blood (Mackie \& McCartney, 1948) was added.

Organisms. The avirulent Tijwidej smooth (TS) strain of Pasteurella pestis and the virulent L 37 strains were used. The stock cultures were maintained as freeze-dried cultures or in stab cultures on the solid medium at $4^{\circ}$.

Preparation of inoculum. A slope of the solid medium was inoculated from the stock culture. The slope culture was transferred to a conical flask containing $12.5 \mathrm{ml}$. liquid medium with the following changes: $\mathrm{KH}_{2} \mathrm{PO}_{4}, 3 \cdot 2 \mathrm{~g}$./l.; $\mathrm{Na}_{2} \mathrm{HPO}_{4}, 13 \cdot 6$ g./l.; casein hydrolysate $10 \mathrm{~g} . / 1$; glucose replaced by galactose, $10 \mathrm{~g} . / 1$; glycine and $\mathrm{CaCl}_{2}$ omitted. These changes were used principally to increase the buffer capacity and to restrict the growth to be more in keeping with the amount of available oxygen. After 24 hr. gentle reciprocal shaking (throw 0.6 in., 100 cycles/min.) the culture was transferred to $100 \mathrm{ml}$. of the same medium in a $2 \mathrm{l}$. bottle and shaken gently for $24 \mathrm{hr}$. when the culture was used to inoculate the continuous flow culture, $2 \mathrm{l}$. in volume. Initially, to ensure growth, excess aeration had to be avoided; for the first 2 or 3 generations a sulphite oxidation value of $5 \mathrm{mmole} \mathrm{O}_{2} / \mathrm{l}$./hr. was adequate, with no air flow through the culture vessel.

Antigenic analysis. The organisms were prepared by centrifuging down and drying with acetone at $-20^{\circ}$. The supernatant liquid was examined after it had been freed from organisms by membrane filtration.

Qualitative antigenic analysis was carried out by the Ouchterlony agar gel diffusion method as described by Crumpton \& Davies (1956) . Photographic records were made at about the fourth day. For the detection of $\mathrm{V}$ antigen the micro gel diffusion method of Mansi (1958) with $4 \mathrm{~mm}$. between wells was used for economy of antiserum and antigens. The diffusions for qualitative analysis were carried out at ambient temperature $\left(c . \mathbf{2 2}^{\circ}\right)$. For the identification of antigens other than $\mathrm{V}$ antigen a standard line pattern obtained with TS organisms and antiserum provided by Dr D. A. L. Davies (this Department) was used. For the detection of $\mathrm{V}$ antigen a standard line pattern showing $V$ and $W$ antigens only was obtained with serum and organisms provided by Dr T. W. Burrows (this Department). The organism preparations of Davies \& Burrows are referred to as the standard batch culture preparations.

Methods of quantitative antigenic analysis were developed by using the micro gel diffusion method of Mansi (1958) with specific antisera. The method consisted of comparing the highest dilution of the standard batch culture preparation of antigen which would give a line on the plate not coincident with the antigen well, with the highest dilution of the sample which did likewise. The unit of antigen was defined as the amount present in $1 \mathrm{mg}$. of the standard batch culture preparation; the units 
of antigen/mg. sample were calculated from the dilutions. The factor between antigen dilutions was 2 . The distance between wells on the plate was $2 \mathrm{~mm}$. Fraction I, antigen 4 and $V$ antigen were estimated in this way. The diffusion temperature for the quantitative assays of fraction $I$ and antigen 4 was $37^{\circ}$ for 4 and $3 \mathrm{hr}$., respectively. The diffusion of the $\mathrm{V}$ antigen was at $c .22^{\circ}$ for $18 \mathrm{hr}$.

\section{RESULTS}

\section{Growth of the organism}

The average yield of either strain when there was an excess of available oxygen was $5.5 \mathrm{mg}$. dry wt. $/ \mathrm{ml}$. at $28^{\circ}$ and $3.7 \mathrm{mg}$. dry wt. $/ \mathrm{ml}$. at $37^{\circ}$. This difference between the yields expresses quantitatively the known fact that growth of Pasteurella pestis is poorer at $37^{\circ}$ than at $28^{\circ}$. The mean total number of organisms/mg. dry wt. was $2.5 \times 10^{9}$.

With an excess of available oxygen the oxygen uptake rate was $29 \mathrm{mmole} / \mathrm{l}$./hr. at either temperature. All the results with the TS strain were obtained with excess of available oxygen, that is, with respiration unlimited by oxygen supply. In work with the L37 strain the oxygen uptake rate was limited to 9 mmole/l./hr. when it was found that, with one exception noted below, an excess of oxygen was not essential to the production of the antigens in which we were interested. Limitation of the aeration had the advantage of making foam control easier. This restriction of the oxygen supply decreased the dry wt. yield of organism by $35 \%$.

The yield of organism was independent of the $\mathrm{pH}$ value in the range $\mathrm{pH} 6 \cdot 3-7 \cdot 3$. The TS strain was grown with undiminished yield at $\mathrm{pH} 5.9$ and $37^{\circ}$. An advantage of using $\mathrm{pH}$ control instruments was that glucose could be used as a carbon source. Previous workers, without using this control method, found that acid production from glucose soon stopped growth; this difficulty was previously overcome by using galactose as a carbon source.

Apart from the effect on the yield of organism, increase in the temperature from $28^{\circ}$ to $37^{\circ}$ also caused a severe shock to the culture. This shock, which was particularly marked in growing cultures supplied with an excess of oxygen, was characterized by a high death-rate of the organisms, the appearance of much cell debris, much foaming, and decreases in dry wt. and oxygen uptake to much below the eventual steady-state values. This shock was largely avoided when growth was limited by the oxygen supply.

\section{Production of antigen 4}

The production of antigen 4 was dependent on $\mathrm{pH}$ value and temperature. The $\mathrm{pH}$ value dependence is illustrated in Fig. 1. Production of antigen 4 was completely suppressed at $\mathrm{pH}$ values above $6 \cdot 9$. The optimum $\mathrm{pH}$ value for antigen 4 production was $\mathrm{pH} \mathbf{5 \cdot 9}$, at which value the amount of antigen present in the organisms was six times greater than the amount in the standard batch culture preparation. The supernatant fluid contained a large amount of the antigen, about twice the amount found in the organisms. The dialysed solids of the supernatant fluid at pH $\mathbf{5 \cdot 9}$, we are informed by Dr M. J. Crumpton, were about $20 \%$ pure antigen 4, which means that this fluid was the richest source of antigen.

The effect of $\mathrm{pH}$ value on antigen 4 production by the $\mathrm{L} 37$ strain was the same as with the TS strain. The range of yields of the antigen by the two strains are given in 
Table 1. The yields of antigen 4 are compared at $\mathrm{pH} \mathrm{6.3} \mathrm{instead} \mathrm{of} \mathrm{at} \mathrm{the} \mathrm{optimum}$ $\mathrm{pH}$ value of $5 \cdot 9$, because we found it convenient to work in the range $\mathrm{pH} 6 \cdot 3-7 \cdot 3$ and thus to decrease the time necessary for the $\mathrm{pH}$ changes. The effect of temperature on antigen 4 production is shown in Table 2 . At $28^{\circ}$, a small amount of the antigen was produced at $\mathrm{pH} 6.3$; the production was 20 times greater at $37^{\circ}$. At $28^{\circ}$ and $\mathrm{pH} 7 \cdot 3$ antigen 4 was undetectable. Antigen 4 production in the culture was characterized by a marked increase in the sedimentation time of the organisms; this is in agreement with the finding of Crumpton \& Davies (1957) that this antigen stabilizes a suspension of the organisms.

\section{Production of fraction $I$ and $V$ antigen}

Fraction I production was independent of environmental $\mathrm{pH}$ value in the range $\mathrm{pH} 6 \cdot \mathbf{3}-7 \cdot 3$, but was dependent on the temperature (Table 3). At $28^{\circ}$ only trace

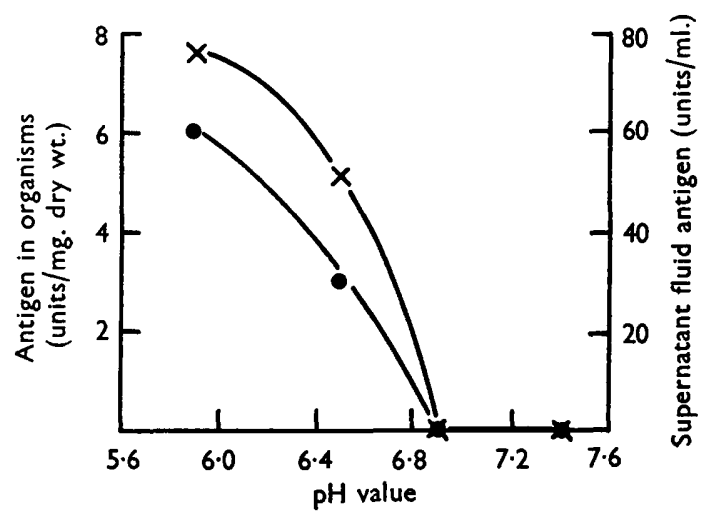

Fig. 1. Antigen 4 production by the TS strain of Pasteurella pestis as a function of $\mathrm{pH}$ value at $37^{\circ}$. Antigen in organism; $x$, supernatant fluid antigen. The values were obtained in the same culture. In this experiment the medium was modified in that the concentrations of casein hydrolysate, glycine and glucose were increased by $83 \%$; and $\mathrm{CaCl}_{\mathbf{2}}$ was omitted.

Table 1. Comparison of antigen 4 production by the TS and L37 strains of Pasteurella pestis at high and low $\mathrm{pH}$ values at $37^{\circ}$

Pooled results from four different cultures of each strain; each set of conditions was reproduced two or more times.

\begin{tabular}{|c|c|c|}
\hline & pH $7 \cdot 3$ & pH 6.8 \\
\hline $\begin{array}{l}\text { Strain of } \\
P . \text { pestis }\end{array}$ & \multicolumn{2}{|c|}{$\begin{array}{l}\text { Antigen in organism } \\
\text { (units/mg. dry wt.) }\end{array}$} \\
\hline & $<0$ & \\
\hline $\mathbf{L}$ & $<0.06$ & $1 \cdot 0-1 \cdot 0$ \\
\hline
\end{tabular}

Antigen in supernatant fluid

\begin{tabular}{|c|c|c|}
\hline \multirow[b]{2}{*}{ TS } & \multicolumn{2}{|c|}{$\begin{array}{l}\text { Antigen in supernatant flu } \\
\text { (units/ml.) }\end{array}$} \\
\hline & $<1.28$ & $2 \cdot 6-12 \cdot 4$ \\
\hline L37 & $<1.28$ & $2 \cdot 6-10 \cdot 2$ \\
\hline
\end{tabular}

The very high values for antigen 4 production reported in Fig. 1 are not comparable with those above because of important differences in media used. 
Table 2. Effect of temperature on antigen 4 production at $p H \mathbf{H} \cdot \mathbf{3}$ by

Pasteurella pestis

\begin{tabular}{|c|c|c|}
\hline & \multicolumn{2}{|c|}{ Growth temperature } \\
\hline & $28^{\circ}$ & $37^{\circ}$ \\
\hline $\begin{array}{l}\text { Strain of } \\
P . \text { pestis }\end{array}$ & \multicolumn{2}{|c|}{$\begin{array}{l}\text { Antigens in organisms } \\
\text { (units/mg. dry wt.) }\end{array}$} \\
\hline TS & $0 \cdot 125$ & $\mathbf{2 \cdot 0}$ \\
\hline \multirow[t]{2}{*}{ L37 } & $0 \cdot 03$ & $\mathbf{1} \cdot \mathbf{0}$ \\
\hline & \multicolumn{2}{|c|}{$\begin{array}{l}\text { Antigen in supernatant fluid } \\
\text { (units/ml.) }\end{array}$} \\
\hline $\begin{array}{l}\text { TS } \\
\text { L37 }\end{array}$ & $2 \cdot 56$ & $10 \cdot 2$ \\
\hline L37 & $<1.28$ & $5 \cdot 1$ \\
\hline
\end{tabular}

The values for each strain are from the same culture, those for $28^{\circ}$ being obtained before those for $37^{\circ}$

Table 3. Effect of temperature on fraction I production by

Pasteurella pestis

$\overbrace{28^{\circ}}^{\text {Growth temperature }}$

$\begin{array}{lll}\begin{array}{l}\text { Strain of } \\ P \text {. pestis }\end{array} & \begin{array}{r}\text { Fraction I in organisms } \\ \text { (units/mg. dry wt.)* }\end{array} \\ \text { TS } & 0-0.03 & 0.25-0.50 \\ \text { L37 } & 0-0.06 & 0.125-0.50\end{array}$

Fraction $I$ in supernatant fluid (units $/ \mathrm{ml}$.)*

$\begin{array}{lll}\text { TS } & 0-0.03 & 1 \cdot 28-2 \cdot 26 \\ \text { L37 } & <0.32 & 0.32-1.25\end{array}$

* Maximum amount in steady states. Pooled results of four cultures of each strain: each set of conditions was reproduced two or more times.

amounts of the antigen were produced; at $37^{\circ}$ the antigen was produced in large amount, though the maximum fraction I content of organisms was only about a half of that of the standard batch culture preparation. About $50 \%$ of the total fraction I antigen content of the culture was present in the supernatant fluid.

$\mathrm{V}$ antigen was not detected in organisms grown at $28^{\circ}$. At $37^{\circ}$ a maximum $\mathrm{V}$ antigen content of 1 unit/mg. dry wt. was obtained; this equals that of the standard batch culture preparation. None of this antigen was detected in the unconcentrated

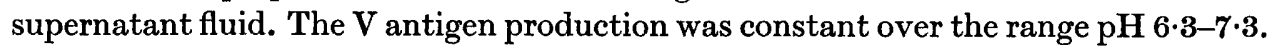

\section{Production of other antigens}

We also identified in our samples antigens $1,2,5$ and 8 as defined by Crumpton \& Davies (1956). Although the amounts of these antigens varied from time to time, their synthesis, with the exception of antigen 5, could not be correlated with any particular conditions. The $W$ antigens of the virulent organism accompanied the $\mathrm{V}$ antigen but, judging by the line intensity in the diffusion analysis, were present in very small amount. 
The synthesis of antigen 5 seemed to be oxygen dependent at $28^{\circ}$ with the L37 strain (the TS strain was not examined in this respect). Organisms grown at $37^{\circ}$ gave a strong antigen 5 line in gel diffusion whether or not growth was limited by oxygen. But at $28^{\circ}$ a strong antigen 5 line was only produced with excess of available oxygen. Crumpton \& Davies (1956) reported that antigen 5 production was highly dependent on temperature; this would appear to be true only when the growth is oxygen limited.

\section{Rate of change in antigenic composition with change in environment}

It is known that after a substrate change there must often be a period of adaptation while the metabolism of the organism adjusts itself to this change. Here we are concerned with the adaptation to a change in the physical environment such as that of temperature or $\mathrm{pH}$ value. There also arose the practical question of how quickly could a change in temperature or $\mathrm{pH}$ value be made without adverse effects on the organism. Generally we found that rates of change in temperature of $1^{\circ}$ and of pH value of $0 \cdot 1$ unit, every $4 \mathrm{hr}$., were tolerated.

In the following discussion it may be borne in mind that, in a continuous culture in a steady state, the rate of antigen production per unit weight of organisms $\left(q_{\mathrm{ag}}\right)$ may be derived from the antigen concentration by the equation which relates rate of product formation with product concentration:

$$
q_{\mathrm{ag}}=\frac{\text { antigen concn. } \times D}{x},
$$

where $D$ is the dilution rate and $x$ the concentration of organism. Hence, if $D$ and $x$ are constant, $q_{\mathrm{ag}}$ is directly proportional to the antigen concentration.

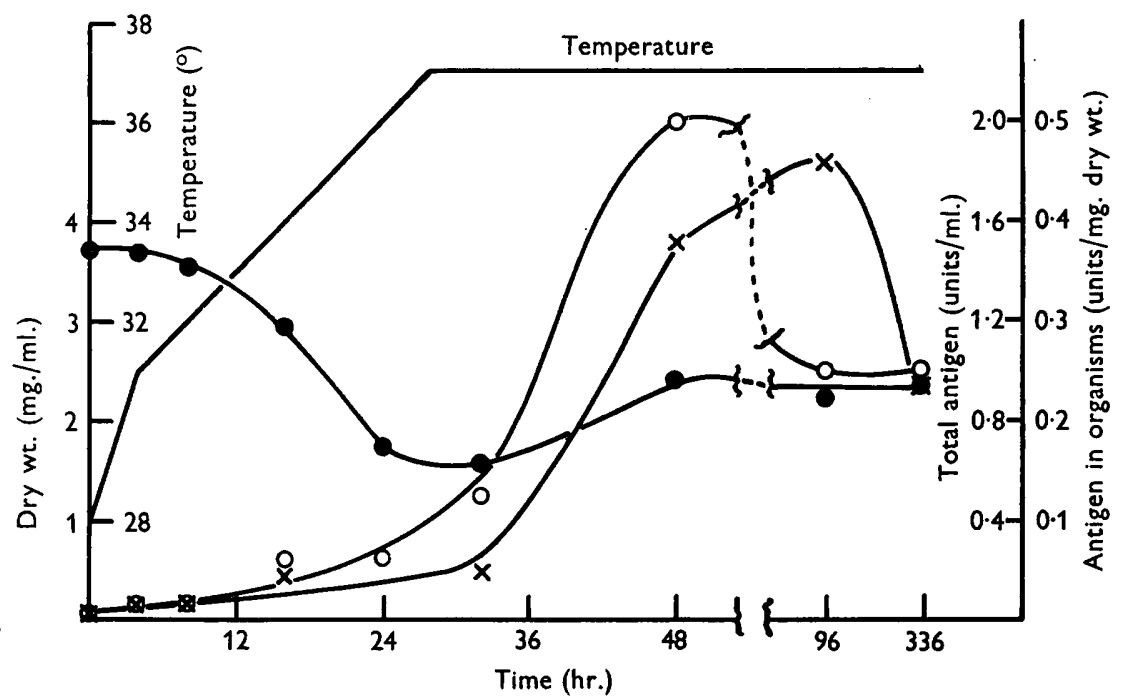

Fig. 2. Fraction I antigen production by strain L 37 of Pasteurella pestis as a function of time on raising the temperature from $28^{\circ}$ to $37^{\circ}$. $O$, Antigen in organism; $\times$, total antigen (supernatant fluid+organism);, , dry wt. of organisms (growth was oxygen limited). 
Changes in the fraction I content and in the dry wt. of organism as functions of time on raising the temperature from $28^{\circ}$ to $37^{\circ}$ are shown in Fig. 2. The main features of the transition are that the dry wt. quickly responded to the temperature change and passed through a minimum before it adjusted itself to the new steadystate value. The production of antigen fraction $I$, however, did not respond as rapidly as the dry wt. but increased rapidly only when the temperature reached $37^{\circ}$. The amount of fraction $I$ antigen in the organisms passed through a maximum. This may be attributed to an initial retardation of diffusion of the antigen from the organism into the supernatant fluid; it was not due to a decrease in the rate of antigen synthesis since the total amount of antigen present increased when the organism antigen content decreased. The fall in total antigen observed between 96 and $336 \mathrm{hr}$. may be attributed to selection of fraction I- organisms, that is, organisms without the ability to produce fraction $I$.

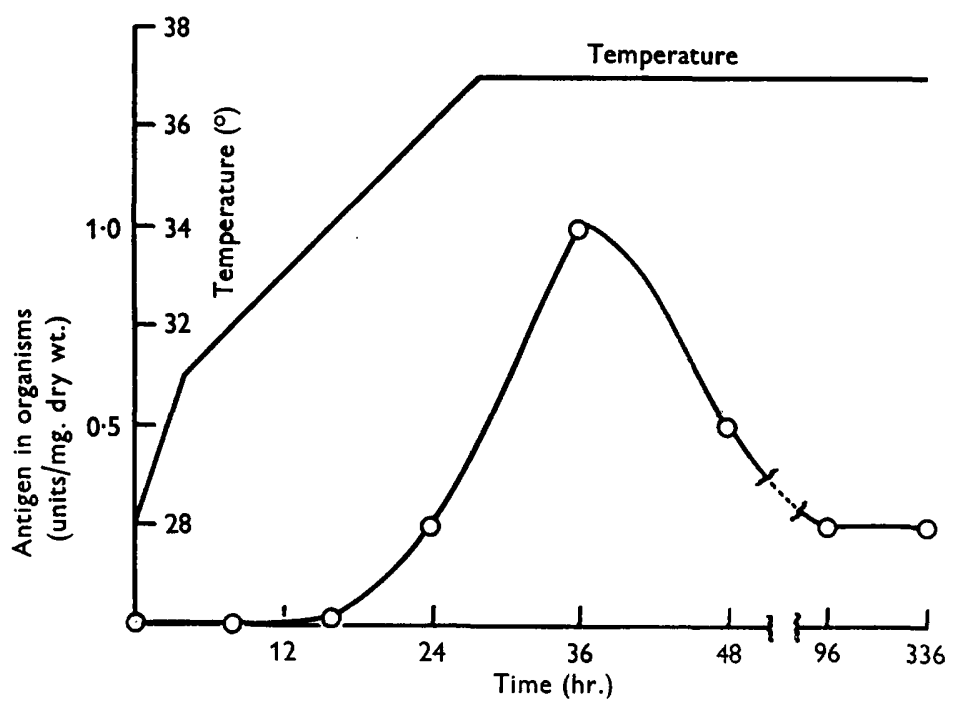

Fig. 3. V antigen production by strain L37 of Pasteurella pestis as a function of time on raising the temperature from $28^{\circ}$ to $37^{\circ}$.

The transition to $\mathrm{V}$ antigen production is shown in Fig. 3. When the temperature exceeded $34^{\circ}$ the production of $\mathrm{V}$ antigen rose rapidly (in 4 generation times) from zero to maximum. Unlike antigen fraction $I, V$ antigen was not detected in the supernatant fluid. To account for the peak value in the $V$ antigen content it seems necessary to postulate that the initial rate of antigen production exceeded the steady-state rate.

The transition to antigen 4 production is shown in Fig. 4. The transition began when the $\mathrm{pH}$ value fell below $\mathbf{6 \cdot 9}$. With decrease in $\mathrm{pH}$ value the antigen production rate rose rapidly to the maximum. Again, the results show that in the transition the antigen content of the organisms passed through a maximum in a way similar to the transition to fraction I antigen production. The reversibility of the transition to antigen 4 production is illustrated in Fig. 4. On raising the $\mathrm{pH}$ value from $6 \cdot 3$ to $7 \cdot 2$ antigen 4 production stopped and the residual antigen was diluted out. 


\section{Maintenance of antigen synthetic abilities; variation and selection}

An organism, which, given the right environment, is able to produce fraction $\mathbf{I}$ antigen is termed a fraction I + organism; an organism which has lost this ability is termed a fraction $\mathrm{I}-$ organism. The terms $\mathrm{V}+$ organism and $\mathrm{V}-$ organism are derived similarly.

During cultivation at $37^{\circ}$ the organisms gradually lost their abilities to produce both fraction $I$ and $V$ antigens as shown in Tables 4 and 5 . These changes we
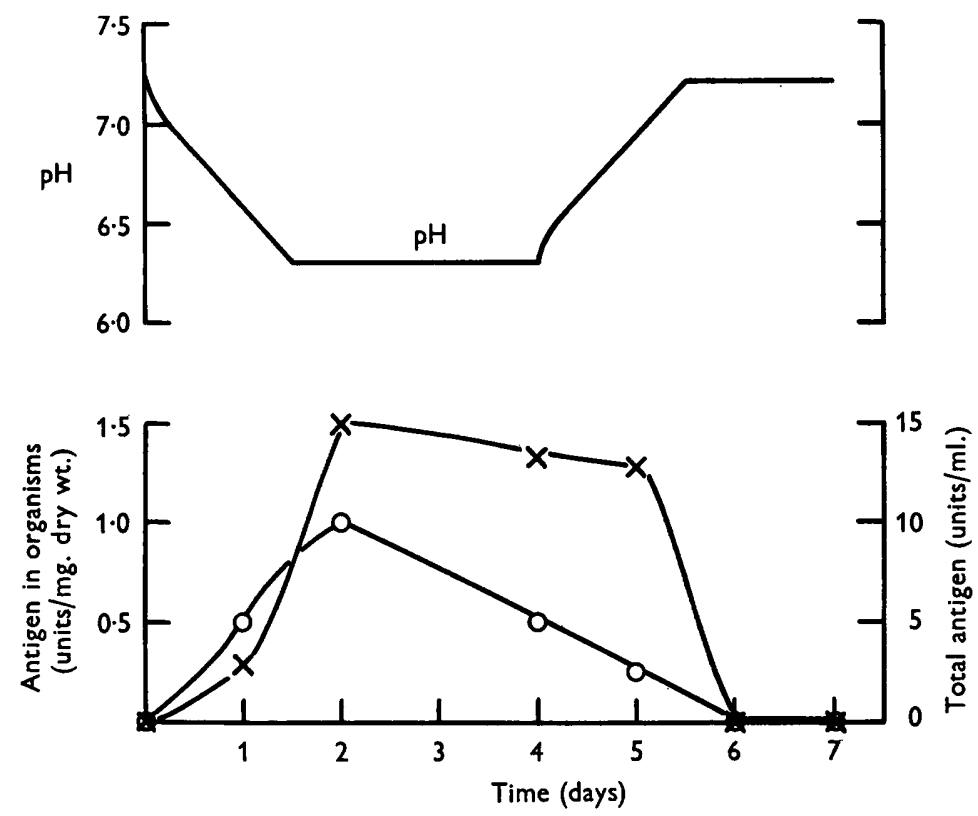

Fig. 4. Antigen 4, production by strain TS of Pasteurella pestis as a function of time with pH changes. $O$, antigen in organism; $x$, total antigen (supernatant fluid +organism). The dry wt. concn. was $2.6 \mathrm{mg}$. $/ \mathrm{ml}$. (in this medium the casein hydrolysate, glycine and glucose concentrations were decreased by one-third).

attribute to selection against fraction $I+$ and $V+$ organisms. In the L37 culture (Table 4) there was a $75 \%$ decrease in the concentration of fraction I antigen, and consequently in the rate of production, in 59 generations (69th to 128th). Selection against $\mathrm{V}+$ organisms was slower than that against fraction $\mathrm{I}+$ organisms.

At $28^{\circ}$ selection against fraction $\mathrm{I}+$ and $\mathrm{V}+$ organisms did not occur. It was possible to grow the organism for any length of time (at least up to 111 generations) at $28^{\circ}$ without affecting the ability to produce fraction I antigen when the temperature was raised to $37^{\circ}$. Ability to produce $V$ antigen was unaffected by cultivation of the organism at $28^{\circ}$ for at least 55 generations.

The antigen 4 production by the culture over a long period is shown in Table 5, which shows that there was no significant loss in the ability to produce antigen 4 after 210 generations. Hence antigen 4 production may be classed as a stable function of the culture under the conditions used. 
Practically all the antigen synthetic functions other than those for fraction $I$ and $\mathrm{V}$ antigens seemed to be stable over long periods under the conditions used, judging by the qualitative analyses of line patterns in gel diffusion. In TS cultures after about 150 generations at different $\mathrm{pH}$ values and temperatures, ten antigens of the original twelve were detected; fraction I antigen was one of the missing components. Similarly, in L 37 cultures, thirteen antigens of the original sixteen were retained, fraction $\mathrm{I}$ and $\mathrm{V}$ antigens being two of the missing components.

Table 4. Maintenance of antigen synthetic abilities over long periods by strain L37 of Pasteurella pestis

$\begin{array}{cccc}\begin{array}{c}\text { Culture } \\ \text { age } \\ \text { (hr.) }\end{array} & \begin{array}{c}\text { No. of } \\ \text { generations }\end{array} & \begin{array}{c}\text { Fraction I antigen } \\ \text { in organisms } \\ \text { (units/mg. dry wt.) }\end{array} & \begin{array}{c}\text { V antigen } \\ \text { in organisms } \\ \text { (units/mg. dry wt.) }\end{array} \\ 4.55 & 69 & 0.25 & 0.25 \\ 695 & 104 & 0.25 & 0.25 \\ 790 & 118 & 0.125 & 0.50 \\ 862 & 128 & 0.062 & 0.25 \\ 1462 & 215 & <0.007 & 0.125\end{array}$

The temperature was $37^{\circ}$ from the 55 th to the 128th generation, and from the 166th to the 215th; otherwise it was $28^{\circ}$.

Table 5. Maintenance of antigen synthetic abilities over long periods by strain TS of Pasteurella pestis

$\begin{array}{cccc}\begin{array}{c}\text { Culture } \\ \text { age }\end{array} & \begin{array}{c}\text { No. of } \\ \text { (hr.) }\end{array} & \begin{array}{c}\text { Fraction I antigen } \\ \text { in organisms }\end{array} & \begin{array}{c}\text { Antigen 4 } \\ \text { in organisms } \\ \text { generations }\end{array} \\ 214 & & \text { (units/mg. dry wt.) } & \text { Steady-state concentrations } \\ 238 & \mathbf{3 6 . 5} & \mathbf{0 . 2 5} & \text { N.R. } \\ 286 & 44 & 0.25 & \text { N.R. } \\ 310 & 47 & 0.06 & 0.50 \\ 363 & 55 & 0.06 & \text { N.R. } \\ 622 & 92 & <0.007 & \text { N.R. } \\ 646 & 96 & <0.007 & 2.0 \\ 670 & 99 & <0.007 & 1.0 \\ 1030 & 151 & <0.007 & \mathbf{2 . 0} \\ 1438 & 210 & <0.007 & 0.5\end{array}$

The temperature was $37^{\circ}$ from the 16 th to the 55th generation, from the 89th to the 151st, and from the 197th to the 210 th; otherwise it was $28^{\circ}$.

The $\mathrm{pH}$ value of the culture was $6 \cdot 3$ when antigen 4 production was determined and either pH 6.3 or $7 \cdot 3$ when fraction $I$ and $V$ antigens were determined.

N.R. means no result.

\section{DISCUSSION}

Conditions for producing various antigens. A pH value below 6.9 seems essential for the production of antigen 4, this fact and the pH-time curves for growth in batch cultures (unpublished work of Ross, Hakes \& Herbert of this Laboratory) explain the apparently exacting requirements for antigen 4 production which Crumpton \& Davies (1956) observed. When galactose is the carbon source it takes about $16 \mathrm{hr}$. for the $\mathrm{pH}$ value to fall below 6.9 from the initial value $7 \cdot 5$; this 
accounts for the time lag before the appearance of antigen 4 in the cultures of Crumpton \& Davies. The absence of antigen 4 from broth agar cultures may be attributed to the absence of galactose or glucose from the medium since, in the absence of the sugar, there is no acid production and the $\mathrm{pH}$ value remains too high for antigen 4 production.

The identity between the conditions necessary for the change to antigen 4 production, and those which Aronson \& Bichowsky-Slomnicki (1960) found to cause a marked lowering of the electrophoretic mobility of $\boldsymbol{P}$. pestis, suggests that antigen 4 may be the surface component postulated by Aronson \& Bichowsky-Slomnicki to explain the change in electrophoretic mobility. However, one piece of evidence seems at variance with this interpretation, namely that the change in electrophoretic mobility was observed to occur not only with the TS, L37 and other strains producing antigen 4, but also with the TRU strain which Crumpton \& Davies (1956) classified as a non-producer of antigen 4 . This discrepancy may be explained by the presence in the TRU organism of a substance derived from antigen 4 by a slight molecular change sufficient to destroy the antigen specificity but not sufficient to change the electrophoretic properties of the molecule.

The results of Crumpton \& Davies (1957) show that antigen 4 is important in the production of immunity to Pasteurella pestis by the live TS strain in mice. If production of immunity in this way involves some in vivo production of antigen 4 it must mean that the organism finds some environment in vivo where the $\mathrm{pH}$ value is less than $6 \cdot 9$, that is, considerably lower than the so-called 'physiological' value, $\mathrm{pH} 7 \cdot 4$.

The qualitative differences in antigenic composition which can be induced by environmental changes make it appear that this is a technique which deserves to be used more in antigenic analysis in the same way as genotypic variants are used. Clearly we have not studied all the environmental changes of interest. In particular it would be of value to study the effect of inorganic salt changes in view of their effects on the antigenic composition of Haemophilus (Lacey, 1953) and Paramecium (Beale, 1954). Variation in antisera to organisms grown in differently controlled environments is another aspect which requires study, for example, to see whether new antigens are produced.

Transition from one antigenic state to another. It is important to notice that the highest concentrations of some antigens may arise not in any steady states but in the transition from one steady state to another. Practical use might be made of this finding to produce the highest possible yields of some antigens. It may also help to account for the differences between the antigenic composition of organisms grown in batch culture and that of organisms grown in a continuous steady-state culture, since transitional states may occur in batch culture.

Evolution in continuous flow cultures. In long-term cultures (the longest used here was $2300 \mathrm{hr}$.; 330 generation times) such as we have been studying, selection of variants is a problem to be reckoned with. It has been previously reported (Taylor, 1933) that Pasteurella pestis loses virulence more rapidly by in vitro culture at $37^{\circ}$ than at $27^{\circ}$. An explanation of this is provided by the observation of Burrows (1960) that $\mathrm{V}$ - and $\mathrm{W}$ - organisms have a selective advantage over their $\mathrm{V}+$ and $\mathrm{W}+$ counterparts, when mixed cultures are incubated at $37^{\circ}$, though not at $28^{\circ}$. Our observations on selection in continuous flow cultures confirm the observations of 
Burrows and, furthermore, show that fraction $I-$ organisms have a selective advantage over the fraction $\mathrm{I}+$ organisms at $37^{\circ}$; this gives an added reason why virulence is lost during in vitro culture at $37^{\circ}$. If it be desired both to preserve the abilities to synthesize $\mathbf{V}$ and fraction $I$ antigens and to produce these antigens in a continuous flow process, it would seem to require more than one stage. The organisms would have to be grown at $28^{\circ}$ to prevent selection against $\mathrm{V}+$ and fraction $\mathrm{I}+$ organisms and then transferred to a second stage at a higher temperature for the production of the desired antigens.

We thank Drs D. A. L. Davies, M. J. Crumpton and T. W. Burrows for initiating us into antigenic analysis of Pasteurella pestis, and for the supply of standard antigen preparations and antisera.

\section{REFERENCES}

Aronson, M. \& Bichowsky-Slomnicki, L. (1960). Temperature and pH-dependent changes of electrophoretic mobility of Pasteurella pestis. J. Bact. 79, 734

Brale, G. H. (1954). The Genetics of Paramecium aurelia. Cambridge University Press.

Burrows, T. W. (1860). Virulence determinants in Pasteurella pestis and Past. pseudotuberculosis. Hafjine Institute Diamond Jubilee Symposia, no. 14.

Burrows, T. W. \& Bacon, G. A. (1956). The basis of virulence in Pasteurella pestis: an antigen determining virulence. Brit. J. exp. Path. 37, 481.

Callow, D. S. \& PIRT, S. J. (1956). Automatic control of $\mathrm{pH}$ value in cultures of microorganisms. J. gen. Microbiol. 14, 661.

Caliow, D. S. \& PIRT, S. J. (1961). Developments in apparatus for the culture of microorganisms: design features of a laboratory two-stage continuous flow culture apparatus. J. axpl. Bact. 24, in the Press.

Crumi ton, M. J. \& Davies, D. A. L. (1956). An antigenic analysis of Pasteurella pestis by diffusion of antigens and antibodies in agar. Proc. roy. Soc. B, 145, 109.

Crumpion, M. J. \& Davies, D. A. L. (1957). A protein antigen associated with smooth colony forms of some species of Pasteurella. Nature, Lond. 180, 863.

Elsworth, R., Meakin, L. R. P., Pirt, S. J. \& Capell, G. H. (1956). A two litre scale continuous culture apparatus for micro-organisms. J. appl. Bact. 19, 264.

LACEY, B. W. (1953). Three-dimensional patterns of antigenic modulation of Haemophilus pertussis, $\boldsymbol{H}$. parapertussis and $\boldsymbol{H}$. bronchisepticus. J. gen. Microbiol. 8, iii.

Mackie, T. J. \& McCartney, J. E. (1948). Handbook of Practical Bacteriology, 8th edn. Edinburgh: E. and S. Livingstone.

MaNsi, W. (1958). Slide gel diffusion precipitin test. Nature, Lond. 181, 1289.

Ogburn, C. A., Harris, T. N. \& Harris, S. (1958). Extracellular antigens in steady-state cultures of the hemolytic streptococcus: production of proteinase at low pH. J. Bact. 76, 142.

Pirt, S. J. \& Callow, D. S. (1958). Exocellular product formation by micro-organisms in continuous culture. I. Production of 2:3-butanediol by Aerobacter aerogenes in a singlestage process. J. appl. Bact. $21,188$.

PirT, S. J. \& Callow, D. S. (1959). Exocellular product formation by micro-organisms in continuous cultures. II. Production of 2:3-butanediol from sucrose by Aerobacter aerogenes in a two-stage process. Selected Scientific Papers, Vol. 2, part 2. Rome: Istituto Superiore di Sanità.

Rowland, S. (1914). The morphology of the plague bacillus. J. Hyg., Camb. 14, 418.

Scrütze, H. (1932). Studies in B. pestis antigens: I. The antigens and immunity reactions of B. pestis. Brit. J. exp. Path. 13, 284.

TAYLOR, J. (1933). Haff kine's plague vaccine. Indian med. Res. Mem. no. 27, 108. 